\title{
Importance Analysis of Making WeChat as a Platform of Building Harmonious Teacher-Student Relationship in Chinese Colleges and Universities
}

\author{
Jing Li \\ College of Economics and Management, Shangqiu Normal University, Shangqiu, China \\ Email:1j010712@163.com
}

How to cite this paper: Li, J. (2018). Importance Analysis of Making WeChat as a Platform of Building Harmonious Teacher-Student Relationship in Chinese Colleges and Universities. Creative Education, 9, 1969-1977.

https://doi.org/10.4236/ce.2018.913144

Received: September 27, 2018

Accepted: October 21, 2018

Published: October 24, 2018

Copyright $\odot 2018$ by author and Scientific Research Publishing Inc. This work is licensed under the Creative Commons Attribution International License (CC BY 4.0).

http://creativecommons.org/licenses/by/4.0/ (c) (i) Open Access

\begin{abstract}
Harmonious teacher-student relationship is the basic sign of the healthy development of the school, and is the fundamental requirement to achieve the national education goals. Great changes of the economic and social environment make teacher-student relationship on the abnormal development road, in order to build a harmonious relationship between teachers and students, we must take on the development achievements of information technology brings. As a representative of modern information technology, WeChat provides a virtual scene of teachers and students to be equal, provides the tool of improving the teaching method, and provides a platform of teachers and students to communicate with each other. In order to play the positive role of WeChat, we can make an article from constructing the university WeChat public platform, reforming promotion mechanism of teachers' professional title, and improving the teachers' ability to use information technology.
\end{abstract}

\section{Keywords}

Harmonious Teacher-Student Relationship, China, WeChat, Policy

Recommendations

\section{Introduction}

The teacher-student relationship is the most central and basic relationship in interpersonal relationships. "The teacher-student relationship is no less important to the quality of education, the effectiveness of teaching, and the growth of students. It is no less important than the value of air to people" (Zhai, 1993). The 
respect for teachers has always been a fine tradition in China. With the gradual and in-depth development of the market economy, great changes have taken place in society, and explicit changes have taken place in the school environment. The relationship between teachers and students in universities has become more and more utilitarian. We should revisit the cornerstone of the educational edifice of teacher-student relations. The harmonious teacher-student relationship is the fundamental symbol of the healthy development of the school and is a fundamental requirement for achieving National Education goals. In order to build a harmonious teacher-student relationship, we must find out the main factors that restrict its benign development on the basis of the definition.

This article consists of four parts. Firstly, it defines the connotation of harmonious teacher-student relationship and analyzes the main factors. Secondly, the main function of WeChat in constructing harmonious teacher-student relationship is analyzed. Thirdly, the author puts forward some policy suggestions to promote the construction of harmonious teacher-student relationship. Finally, the research results obtained in this paper are theoretically summarized.

\section{The Definition of Harmonious Teacher-Student Relationship and the Analysis of Main Factors Restricting Its Benign Development}

In view of the relationship between teachers and students, many scholars have conducted a targeted discussion. Some scholars believe that the relationship between teachers and students like friends, relatives, brothers and sisters. Some scholars believe that the relationship between teachers and students like production relations, contractual relations, and ethical relations (Duan, 2014). Many teachers advocate that "teachers are teachers and students are students," the relationship can not be broken. Can these relationships truly express the true meaning of harmonious teacher-student relations? This article holds that harmonious teacher-student relationship means mutual respect, mutual trust, freedom and equality formed in the course of teaching and students' school life and centered on serving students wholeheartedly, with advanced teaching methods as its guarantee, and with smooth communication as its means. Harmonious teacher-student relations should have the following basic characteristics: equal status, smooth communication, mutual respect. Equal status of teachers and students is a prerequisite for mutual respect. If the status is not equal, it is impossible to achieve mutual respect between teachers and students. Smooth communication is the main way to solve problems and conflicts. It is the basic way to realize mutual respect between teachers and students.

Looking at the present situation of teacher-student relations in Chinese universities, it can be seen that there are serious problems in teacher-student relations: the relationship between teachers and students is indifferent, teachers despise students, students abuse teachers, criticize each other, and even physical conflicts occur from time to time. These phenomena indicate that the relationship 
between teachers and students has become increasingly tense. In order to build a harmonious teacher-student relationship, this paper tries to use the achievements of modern information technology to find a solution to the problem. At present, WeChat has grown into the most fashionable, the most convenient mobile dating software. "WeChat is such a social network that relies on social software connections to build 'wet' relationships between people and create a 'wet' environment." (Tan, 2013) The application of WeChat will certainly play a positive role in the construction of a harmonious teacher-student relationship. In order to give full play to the maximum function of WeChat, we must first understand the main factors that restrict the healthy development of teacher-student relations in universities.

\subsection{Role Positioning Is Putting the Cart before the Horse}

The role positioning of teachers and students has always been the focus of attention of people from all walks of life. Teachers have always been in a strong position due to their advantages in terms of age, knowledge, and authority. With the strengthening of this status, the relationship between teachers and students has evolved into a relationship to rule or be ruled, and students have become objects of domination. With the development of this relationship, both teachers and students acquiesced in this relationship, which is the root cause of the tension between teachers and students. Zhao Wei uses the Liaoning Normal University as an investigation object to investigate the teacher-student relationship. In the survey of the question "In the teacher-student interaction, you think your status," $55.17 \%$ teachers believe that the status of teachers and students is very equal and relatively equal. The students who agreed with this answer are only 42.37\%; There are only $12.07 \%$ teachers who believe that the status of teachers and students is not too equal or very unequal, while students take $30 \%$ (Zhao, 2010). This result can reflect the fact that the unequal teacher-student relationship does exist. From the human perspective, teachers and students are individuals who have the ability to think independently. The status of teachers and students should be equal, not the distorted and unequal relationship to rule or be ruled. Students are the main body of the school. There will be no school without students, and there will be no teachers without schools. Fair and Democratic teacher-student relationship is the fundamental guarantee for the long-term development of the school.

\subsection{The Teaching Model Is Simple and Old-Fashioned}

Chinese college teachers are used to the teaching mode of full church. Teachers speak on the podium and students listen below. Due to the disadvantaged position of students and the weak character of students, many students dare not question the teaching methods of teachers. Over time, this kind of teaching mode "You talk about your classes, I do my work" is widely found in various colleges and universities. This kind of teaching method suppresses the growth of 
students' personality and inhibits students' subjective initiative, thus causing students to have a loathing mentality, which will eventually lead to students aversion to teachers. Teaching is not a one-way movement process from teaching to learning. Instead, it should be a two-way dynamic process that repeats and promotes each other. Since there is no effective teacher evaluation system, even if the teacher evaluation system is built, there is no effective reward and punishment system related to the teaching effect. Teachers will not care about the real effect of teaching. Moreover, the promotion of titles and positions of many college teachers is more focused on the level of scientific research than the level of teaching. This evaluation system leads to no motivation for teachers to improve the quality of teaching, and students have no right to ask teachers to adopt the teaching methods they like. Therefore, it is not surprising that there exists a phenomenon of "teachers in the classroom and strangers outside the classroom" in colleges and universities.

\subsection{Single and Narrow Channel of Communication}

Good communication is a prerequisite for the formation of a harmonious teacher-student relationship. Obviously, the channels of communication between teachers and students are narrow and single. Colleges and universities generally do not implement seating system, that is to say, teachers will only appear in classrooms until class time. Classrooms may be the only place where students can communicate with teachers, but the content of communication is also limited to textbook knowledge, if there is no curriculum arrangement. Teachers usually work in their homes. Students only have the opportunity to communicate with the teacher at a limited time and in a fixed place. In the four years of college, many students have never communicated with their teachers. The main reason is that teachers should bear the main responsibility. Many teachers are reluctant and disdainful to communicate with students and believe that communicating with students is a waste of time. In fact, teachers can find students' interests in the process of communicating, and can effectively improve teaching methods, improve teaching efficiency, and truly realize teaching success.

\section{WeChat: A Catalyst for Improving Teacher-Student Relations}

From the above analysis, it can be seen that the main factors that restrict the healthy development of teacher-student relations in colleges and universities are wrong role positioning, single teaching methods, and narrow communication channels. In order to shorten the psychological distance between teachers and students and form a harmonious teacher-student relationship, it is necessary to take wholeheartedly serving students as the starting point and adopt methods that students can and are willing to accept to ease the tense relationship between teachers and students. The development of information technology has broken the social pattern of human interaction and influenced human behavior choices. We can also use the results of the development of information technology to 
solve the discordant relationship between teachers and students.

Since its launch in January 2011, WeChat has become the most popular communication tool, as can be seen from the growth in its user base. In March 2012, the number of WeChat registered users exceeded 100 million; In September 2012, it exceeded 200 million; In January 2013, it exceeded 300 million; In October 2013, there were more than 600 million people and 100 million active users per day. WeChat had covered more than 200 countries and regions around the world, domestic and foreign monthly active users exceeded and more than 270 million (Wang \& Li, 2014). WeChat users are mainly young and middle-aged, and students occupy a dominant position among young people. Since there is a campus network in colleges and universities, students can use WeChat for free. This low-cost, easy-to-use feature quickly makes it a platform for communication that students like. The birth of WeChat provides an opportunity for the development of harmonious teacher-student relations.

\subsection{WeChat Provides a Virtual Scene of Equality between Teachers and Students}

The teacher-student relationship is an equal relationship, not a relationship to rule or to be ruled. The first meaning of equality between teachers and students is that teachers and students can become friends. Through WeChat, teachers can add students as friends, and students can also add teachers as friends. When teachers apply through students' friends plus, the activity itself is an encouragement for students. In a virtual scene, the teacher and the student became friends, and they could speak freely to each other, breaking the fear of the middle school student to the teacher in the face-to-face teaching mode, and narrowing the psychological distance between the student and the teacher. The second layer of equality between teachers and students means that the teacher must be fair to the students, although the teacher has greater rights in the definition of the final results of the students, and can affect the evaluation of student scholarships and the selection of student cadres. However, a qualified teacher should treat every student fairly. Justice is a very important feature of the teacher's personality. The Russian educator named Ushinsky once said: "The personality of the teacher toward the young mind is the sun that can not be replaced by anything that is beneficial to development. Educators' personality is all about education." (Nie, 2013) Therefore, teachers should give regular scores based on the usual performance of each student. The students' final examination papers should be objectively graded and should not be mixed with other factors that affect fairness. The teacher should communicate the final score accounting and basic information on WeChat, and carefully answer students' questions, and ask the classmates to supervise the report until the student's doubts are eliminated.

\subsection{WeChat Offers Tools to Improve Teaching Methods}

The backwardness of teaching methods not only makes students weary of learning, but also makes students have an aversion to teachers. For teachers, the traditional 
teaching model must be reformed as soon as possible. The traditional cramming teaching model ignores students' subjective feelings and does not take into account the students' learning interests. Students are not passive recipients of information, and students can choose and process themselves. In today's rapidly changing information age, the classroom taught by teachers can not be limited to the classroom. As we know, the use of QQ group teaching has become a common teaching method in Chinese colleges and universities. WeChat's function is more convenient than QQ, and it is more likely to be favored by students. Teachers can first add their classmates to WeChat's friends and then divide them into three groups: the research group, the professional group, and the start-up group. The research group is mainly students who want to obtain graduate students. The professional group is mainly students who want to be employed in the future. The start-up group is mainly students who intend to start a business in the future. To meet the different needs of these three groups of students, the teacher can set up different topics and discuss them at a fixed time each week. The teachers and students can use text, pictures, voice, video and other means to communicate with each other. In the process of discussion, students can be inspired to learn and can be mobilized their enthusiasm for learning.

\subsection{WeChat Provides a Platform for Communication between Teachers and Students}

The lack of exchange between teachers and students in colleges and universities is the main problem that restricts the construction of harmonious teacher-student relations. Both teachers and students have responsibilities that can't be shirked. The main energy of teachers is on scientific research, and the main energy of students is on how to take examinations for a graduate programme, on how to practice, and on how to take part-time work. The birth of the WeChat tool makes the communication between teachers and students no longer a burden, but a pastime after meals. During the pastime, teachers and students can communicate fully. The main content of communication is often the main method of learning, the discussion of current affairs issues and so on. The exploration of learning methods is of great importance to students. Teaching knowledge is not the most important. Teachers can recommend learning websites and related databases to students. What students need is a method of learning and thinking and is a method of solving problems. Therefore, for a qualified teacher, the conscious shaping of students' thinking patterns is a powerful expression of scientific teaching methods. With regard to the discussion of topical issues, teachers should pay attention to correcting students' wrong outlook on life, values, and world outlook in the process of communicating with students. When it comes to the corruption of officials and the supremacy of money, many students have a one-sided view that many officials are greedy and money is omnipotent. In view of this point of view, teachers should fully listen to students' arguments, explain positive cases in detail, and correct students' wrong understanding in a 
reasoned manner. Teachers can also upload positive materials in WeChat's "circle of friends" in order to resonate among students, thus influence and guide students to form a correct outlook on life, values, and world views.

\section{Policy Recommendations for the Active Role of WeChat}

\subsection{Construction of University WeChat Public Platform}

Universities can establish their own WeChat public number, and there must be specialized technicians responsible for daily management, information release, feedback information collection and so on. The establishment of the WeChat platform can narrow the distance between schools and students and achieve instant and zero-distance communication. Firstly, the school can publish information closely related to the interests of students through the WeChat platform, such as the procedures for the replacement of student cards, the evaluation standards of student scholarships, the selection procedures of the school student union cadres, and the release of lectures and venues for well-known scholars. The timeliness and effectiveness of WeChat enable students to grasp valuable information at the first time. Secondly, schools can listen to students through public platforms, such as the change of the school name, the selection of school songs, and the formulation of campus regulations. All these matters can fully mobilize students' enthusiasm, pool their resources and fully reflect the basic principles of democracy. Finally, the establishment of the school WeChat public platform can promote and deter teachers. Under the influence of the school WeChat platform, teachers will try to use the WeChat platform for teaching services and give full play to the positive role of WeChat. In addition, the establishment of the WeChat platform in colleges and universities has made teachers more dedicated to their duties. If there is an improper violation of the law, teachers can be announced on the WeChat platform. Under the student's complaint, they will certainly be appropriately punished.

\subsection{Reform of the Mechanism for Promotion of Teachers' Professional Titles}

Professional title is a major indicator of a teacher's ability to work. The promotion of professional titles mainly considers two major blocks: teaching and scientific research. In today's Chinese universities, scientific research occupies a large proportion in the evaluation system of professional title promotion, and teaching occupies a lighter weight. Zhou ding, a lecturer at the Institute of history and culture at Sichuan University, has sparked heated debate over whether scientific research or teaching is important. Regardless of what is important, the practice of focusing on scientific research and ignoring teaching is worth thinking about. We must try to reform the current mechanism of teacher title promotion and increase the proportion of teaching in the design of professional title promotion indicators. Otherwise, teachers have no motivation to adopt advanced teaching methods and to improve the quality of teaching. Before reforming the promotion 
mechanism of technical title, we must first establish a scientific evaluation system for teaching effect. This evaluation system should be used in conjunction with online evaluation of students, peer scoring and expert evaluation. Each of these three indicators is given different weights, and the final score of the teacher is calculated. For teachers who have better quality of teaching and who are supported and loved by students, we can take a wise way to promote their titles in an unorthodox manner. For those teachers who lack enthusiasm and whose students have bigger opinions, they should conduct further studies. If they are still not competent, they should be transferred from teaching posts to engage in scientific research.

\subsection{Increasing Capacity to Use Information Technology}

The development of information technology has made it possible for teachers to get rid of old teaching patterns. Colleges and universities can do their work from the following aspects. Firstly, they can encourage young teachers to use WeChat to teach. Young teachers have less resistance to new things and have stronger acceptance ability. Secondly, they can summarize the shortcomings in WeChat teaching and the experience in teaching, and improve the WeChat teaching model as much as possible. Finally, after the WeChat teaching model is perfected, it will be promoted in schools. In the promotion process, we should pay attention to the way to communicate with older teachers. Their resistance to the use of information technology may be stronger. Once teachers have the ability to use advanced information technology to teach, they can not only improve teaching results, increase student satisfaction, narrow the distance between teachers and students, but also effectively grasp the basic conditions for students to use WeChat, and set up a bridge between teachers and students, to guide students to understand WeChat correctly and prevent the phenomenon of "WeChat Control" caused by excessive dependence. We can guide students to form correct network information identification ability, so that students are not misled by wrong information, so that students have the ability to consciously manage themselves in the network virtual environment.

\section{Conclusion}

WeChat teaching can overcome the problem existing in the traditional teaching mode, for example the lack of communicating between teachers and students, poor teaching method etc. WeChat teaching can also enhance students' interest in learning, broaden the channels of teacher-student communication, and provide a platform for building a harmonious teacher-student relationship.

\section{Conflicts of Interest}

The author declares no conflicts of interest regarding the publication of this paper. 


\section{References}

Duan, W. G. (2014). The Three-Dimensional Characteristics of the Teacher-student Relationship in Colleges and Universities and Its Moral Appeal. Qilu Journal, 4, 85-88.

Nie, J. H. (2013). Constructing a Harmonious Teacher-Student Relationship in the New Media Environment. Chinese Higher Education, 6, 59.

Tan, Z. (2013). How Traditional Media Use WeChat to Expand Its Influence-The Media Function and Impact Analysis of WeChat. Chinese Journalists, 5, 101-102.

Wang, Y., \& Li, H. C. (2014). Overview of the Ontological Functions and Applications of WeChat in China. Journal of Kunming University of Technology, 2, 100.

Zhai, B. K. (1993). Pedagogical Collection-International Education Outlook (p. 300). Beijing: People's Education Press.

Zhao, W. (2010). Problems and Influencing Factors in Teacher-Student Relations in Chinese Universities. Modern Education Management, 5, 84. 